\title{
Quality of Service Packet Loss Pada Sistem Home Monitoring Water Flow Berbasis Internet of Things
}

\author{
Andree Fajar Pratama ${ }^{1}$, Syamsyarief Baqaruzi ${ }^{1}$, Ali Muhtar ${ }^{1}$ \\ ${ }^{1}$ Program Studi Teknik Elektro Institut Teknologi Sumatera \\ Email: andree.13117009@student.itera.ac.id, syamsyarief.baqaruzi@el.itera.ac.id, ali.muhtar@el.itera.ac.id
}

\begin{abstract}
The wasteful behavior of clean water causes more and more people to lose access to clean water. The use of water in households so far is still very difficult to manage in using water effectively. Clean water scarcity is a situation when there is a shortage of water to meet human needs. This study built a Home Water Flow Monitoring (HEROIG) system based on the Internet of Things (IoT) to monitor and control water use at home. The hardware uses NodeMCU as a microcontroller and sends the sensing results of the water flow by the water flow sensor which will be sent to the cloud server. Control can be done through the HEROIG android application which has been created and integrated with the IoT system which must work in a good network connection. Testing the quality of the network connection or Quality of Services (QoS), especially packet loss, uses two parameters, namely time and distance. The results of testing the time parameter packet loss by testing once in six seconds in one minute have an average packet loss value of $1.13 \%$, then for testing the distance parameter with the difference of each distance is four meters has an average packet loss value of $0.15 \%$. The test results show that the quality of sending sensor data to the cloud server has a very good category of QoS packet loss parameters, because it has a packet loss value $<3 \%$.
\end{abstract}

Keywords : Water Discharge;Internet of Things;Packet Loss;Quality of Services,Connection

\section{INTISARI}

Perilaku boros air bersih menyebabkan semakin banyak orang yang kehilangan akses terhadap air bersih. Penggunaan air di dalam rumah tangga selama ini masih sangat sulit untuk dilakukan pengelolaan dalam penggunaan air secara efektif. Kelangkaan air bersih adalah situasi saat terjadinya kekurangan air untuk memenuhi kebutuhan manusia. Penelitian ini menmbangun sistem Home Water Flow Monitoring (HEROIG) berbasis Internet of Things (IoT) untuk melakukan monitoring dan controlling penggunaan air pada rumah. Perangkat keras menggunakan NodeMCU sebagai mikrokontroler serta mengirimkan hasil sensing debit air oleh sensor water flow yang akan dikirimkan ke cloud server. Pengontrolan dapat dilakukan melalui aplikasi android HEROIG yang telah dibuat dan terintegrasi dengan sistem IoT yang harus bekerja dalam koneksi jaringan yang baik. Pengujian kualitas koneksi jaringan atau Quality of Services (QoS) khususnya packet loss menggunakan dua parameter yaitu dari waktu dan jarak. Hasil pengujian packet loss parameter waktu dengan pengujian enam detik sekali dalam waktu satu menit memiliki nilai rata-rata packet loss $1,13 \%$, kemudian untuk pengujian parameter jarak dengan selisih setiap jarak adalah empat meter memiliki nilai rata-rata packet loss $0,15 \%$. Hasil pengujian tersebut menunjukan kualitas pengiriman data sensor ke cloud server memiliki parameter QoS packet loss kategori sangat baik, karena memiliki nilai packet loss $<3 \%$.

Kata kunci: Debit Air; Internet of Things;Packet Loss; Quality of Services;Koneksi

Jurnal ELECTRON, Vol. 2, No.1, Mei 2021: 10-17 


\section{PENDAHULUAN}

Air merupakan sumber daya alam yang dapat diperbarui namun seiring pertambahan penduduk dan pembangunan perkotaan yang sangat pesat, keberadan air mulai menurun baik dari segi kuantitas maupun kualitas. Perilaku boros air bersih menyebabkan semakin banyak orang yang kehilangan akses terhadap air bersih. Penggunaan air di dalam rumah tangga selama ini masih sangat sulit untuk dilakukan pengelolaan dalam pengguna air secara efektif. Salah satu faktor internal adalah ketika user lupa mematikan keran ketika menggunakan keran air pada rumah untuk melakukan pengisian air atau kegiatan lainnya, sehingga hal ini membuat kondisi pengguna air dalam rumah tangga adalah penyumbang terbesar terjadinya kelangkaan air.

Kelangkaan air bersih adalah situasi saat terjadinya kekurangan air untuk memenuhi kebutuhan manusia [1]. Kebutuhan air per jiwa per hari menurut SNI 196728.1-2002 tentang Penyusunan Neraca Sumber Daya tercantum 150 liter/jiwa/hari pada kota berpenduduk 1 juta jiwa demikian juga berdasarkan acuan dari Departemen Kesehatan menyebutkan kebutuhan air bersih per jiwa per hari adalah 150 liter. Berdasarkan data Kementerian Pekerjaan Umum dan Perumahan Rakyat (PUPR) pemakaian air rata-rata rumah tangga di perkotaan di Indonesia sebesar setiap orang 144 liter perhari nya. Pemakaian terbesar adalah untuk keperluan mandi sebesar 60 liter perhari perorang atau 45 persen dari total pemakaian air [2]. Hal tersebut perlu adanya kontrol pemakaian dari pengguna air dalam rumah tangga, sesuai dengan poin 6 Suistanable Development Goals yaitu menjamin ketersediaan serta pengelolaan air.

Berdasarkan data pendukung kurangefektifnya penggunaan air bersih pada rumah tangga diatas maka dibutuhkan sistem yang dapat memantau serta mengontrol pengguna air melalui keran air rumah agar lebih efisien dan mencapai target kebutuhan pengguna air sesuai dengan standar yang telah ditentukan. Sistem Home Water Flow Monitoring (HEROIG) sebagai sistem pendukung yang dapat memudahkan user dalam kehidupan sehari-hari yang telah terintgerasi dengan sistem Internet of Things (IoT). Perkembangan sistem IoT dapat memudahkan untuk pemecahan masalah seperti penggunaan air dalam rumah tangga agar memudahkan monitoring dan controlling activity HEROIG dapat melakukan monitoring debit air yang dipakai user, mengeluarkan debit air sesuai dengan kebutuhan user, serta dapat dikendalikan kondisi operasi keran air secara otomatis melalui kendali aktuator servo dengan berbasis Internet of Things (IoT). Sistem Home Water Flow Monitoring (HEROIG) dapat menampilkan informasi debit air secara real time, dengan cara kerja mikrokontroler yang mengirimkan hasil akuisisi data sensor ke cloud server, keberhasilan pengiriman data erat kaitannya dengan kualitas jaringan. Oleh karena itu penting untuk mengetahui kualitas jaringan untuk menentukan Quality of Service melalui pengujian packet loss sistem Home Water Flow Monitoring (HEROIG).

\section{LANDASAN TEORI}

\section{A. Internet of Things}

Internet of Things merupakan sebuah konsep yang bertujuan untuk memperluas manfaat dari konektivitas internet yang tersambung secara terus-menerus. Dengan semakin berkembangnya infrastruktur internet, maka kita menuju babak berikutnya, di mana bukan hanya smartphone atau komputer saja yang dapat terkoneksi dengan internet. Namun berbagai macam benda nyata akan terkoneksi dengan internet. Sebagai contohnya dapat berupa : mesin produksi, mobil, peralatan elektronik, peralatan yang dapat dikenakan manusia (wearables), dan termasuk benda nyata apa saja yang semuanya tersambung ke jaringan lokal dan global menggunakan sensor dan atau aktuator yang tertanam [3]. Internet of Things (IoT) merupakan suatu konsep yang bertujuan untuk memperluas manfaat dari konektivitas internet yang tersambung secara terus menerus. Pada dasarnya IoT (Internet of Things) mengacu pada benda yang dapat diidentifikasikan secara unik sebagai representative virtual dalam struktur berbasis internet [4] .

\section{B. $\quad$ Konsep Cara Kerja IoT}

Cara kerja Internet of Things yaitu dengan memanfaatkan sebuah argumentasi pemrograman yang dimana tiap-tiap perintah argumennya itu menghasilkan sebuah interaksi antara sesama mesin yang terhubung secara otomatis tanpa campur tangan

Jurnal ELECTRON, Vol. 2, No.1, Mei 2021: 10-17 
manusia dan dalam jarak berapa pun. Jaringan internet yang menjadi penghubung di antara kedua interaksi mesin tersebut, sementara manusia hanya bertugas sebagai pengatur dan pengawas bekerjanya alat tersebut secara langsung [5].

\section{Arduino IDE}

Arduino adalah sebuah platform komputasi fisik open source berbasiskan Rangkain input/output sederhana (I/O) dan lingkungan pengembangan yang mengimplementasikan bahasa processing. Arduino dapat digunakan untuk mengembangkan obyek interaktif mandiri atau dapat dihubungkan ke perangkat lunak pada komputer anda (seperti Flash, Pengolahan, VVVV, atau Max / MSP). Rangkaiannya dapat dirakit dengan tangan atau dibeli IDE (Integrated Development Environment) dan arduino bersifat open source [6]. IDE Arduino adalah bagian software open source yang memungkinkan kita untuk memprogram bahasa Arduino dalam bahasa C. Arduino IDE memungkinkan kita untuk menulis sebuah program secara step by step kemudian instruksi tersebut di upload ke papan Arduino [7]

\section{NodeMCU ESP8266}

NodeMCU adalah sebuah platform IoT yang bersifat open source. Terdiri dari perangkat keras berupa System On Chip (SoC) ESP8266-12 buatan Espressif System. Istilah NodeMCU sebenarnya mengacu pada firmware yang digunakan daripada perangkat keras development kit. NodeMCU bisa dianalogikan sebagai board Arduino-nya ESP8266. NodeMCU telah menghubungkan ESP8266 ke dalam sebuah board yang kompak dengan berbagai fungsi layaknya mikrokontroler ditambah juga dengan kemampuan akses terhadap Wifi juga chip komunikasi USB to Serial sehingga untuk memprogramnya hanya diperlukan ekstensi kabel data mikro USB. Secara umum ada tiga produsen NodeMCU yang produknya kini beredar di pasaran: Amica, DOIT, dan Lolin/WeMos. Dengan beberapa varian board yang diproduksi yakni V1, V2 dan V3 [8]

\section{E. $M y S Q L$}

MySQL merupakan database server yang bersifat open source, multiplatform dan berbasis database relasional. MySQL dapat dipakai untuk database pribadi atau pada level korporat berskala kecil hingga besar.
MySQL menggunakan SQL untuk mendukung pengaksesan data (query) [9]. PhpMyAdmin mendukung berbagai operasi MySQL, diantaranya (mengelola basis data, tabel-tabel, bidang (fields), relasi (relations), indeks, user (users), perizinan (permissions), dan lain-lain). Perbedaan phpMyAdmin dengan MySQL terletak pada fungsi. PhpMyAdmin merupakan alat untuk memudahkan dalam mengoperasikan database MySQL, sedangkan MySQL adalah database tempat penyimpanan data. Phpmyadmin sendiri digunakan sebagai alat untuk mengolah/mengatur data pada MySQL [10]

\section{F. Quality of Services}

Quality of Service adalah kemampuan sebuah jaringan untuk menyediakan layanan yang lebih baik lagi bagi layanan trafik yang melewatinya. QoS merupakan sebuah sistem arsitektur end to end dan bukan merupakan sebuah feature yang dimiliki oleh jaringan. Quality of Service suatu network merujuk ke tingkat kecepatan dan keandalan penyampaian berbagai jenis beban data di dalam suatu komunikasi [11].

Quality of Service (QoS) merupakan metode pengukuran tentang seberapa baik jaringan dan merupakan suatu usaha untuk mendefinisikan karakteristik dan sifat pada satu servis. Pada QoS menggunakan teknik untuk mengelola throughput, delay, jitter, dan packet loss dalam jaringan. Kemampuan suatu jaringan untuk menyediakan layanan yang baik dengan menyediakan bandwith, mengatasi jitter dan delay [6]. Parameter dari Quality of Service salah satunya adalah packet loss. Packet loss merupakan suatu parameter yang menggambarkan suatu kondisi yang menunjukkan jumlah total paket yang hilang dapat terjadi karena collision dan congestion pada jaringan

Tabel 1. 1 Kategori Degradasi

\begin{tabular}{|c|c|c|}
\hline $\begin{array}{c}\text { Kategori } \\
\text { Degradasi }\end{array}$ & Packet Loss & Indeks \\
\hline Sangat Bagus & $3 \%$ & 4 \\
\hline Bagus & $15 \%$ & 3 \\
\hline Sedang & $25 \%$ & 2 \\
\hline Buruk & $0 \%$ & 1 \\
\hline
\end{tabular}

Rumus dari packet loss adalah [6]: 
Jurnal ELECTRON, Vol. 2, No.1, Mei 2021, Hal. 10-17

e-ISSN 2622-6588

Packet Loss

$=\frac{\text { Paket data terkirim }- \text { paket data diterima }}{\text { paket data terkirim }} \times 100 \%$

\section{METODE PENELITIAN}

\section{A. Perancangan Sistem Hardware}

Perancangan sistem dibutuhkan sebelum melakukan implementasi alat, penulis melakukan perancangan sistem terlebih dahulu dengan menyusun diagram blok sistem seperti Gambar 3.2

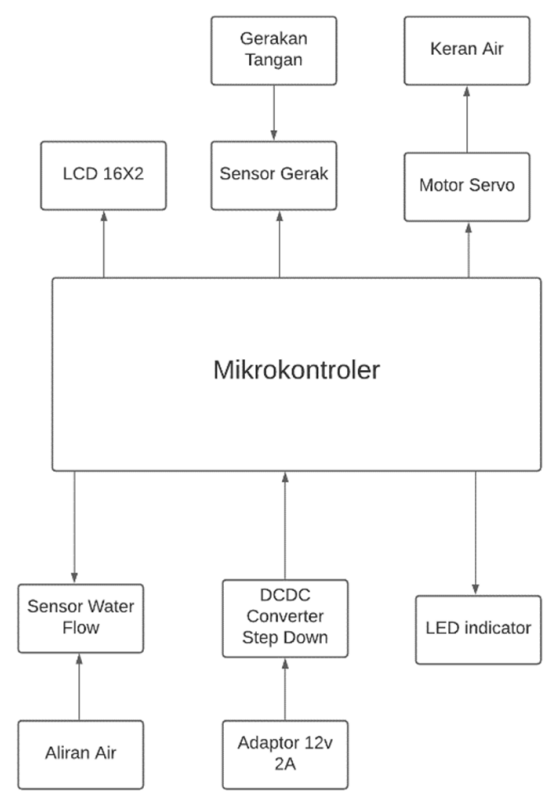

Gambar 3. 1 Blok Diagram Sistem Hardware HEROIG

Blok diagram pada Gambar 3.2 digunakan untuk membangun sistem Home Water Flow Monitoring. Sistem menggunakan papan PCB layout yang telah terintegrasi dan kompatibel dengan mikrokontroler berupa NodeMCU sekaligus terdapat modul wifi untuk menunjang sistem perangkat software. Tampilan pada hardware menggunakan LCD 16X2 menggunkan modul I2C. Sensor yang digunakan terdapat dua buah sensor yaitu sensor water flow untuk membaca aliran debit air yang mengalir, sensor jarak yang digunakan untuk menangkap respon gerakan dari user untuk menghidupkan aktuator ketika sistem dalam kondisi offline. Indikator menggunakan lampu LED, indicator untuk informasi sistem terhubung dengan power dan sistem aktuator dalam kondisi hidup atau mati.

\section{B. Perancangan Sistem Software}

Perancangan sistem software terbagi menjadi sistem database dan sistem aplikasi HEROIG yang saling terintegrasi. Pada Gambar 3.3 adalah flowchart cara kerja aplikasi yang akan dirancang

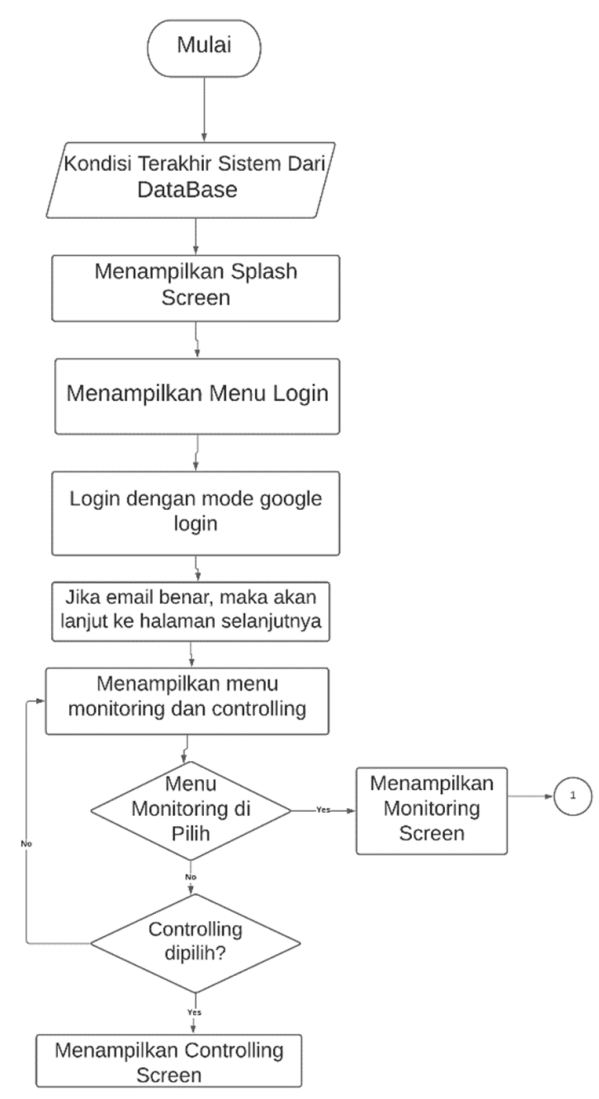

Gambar 3. 2 Diagram Alir A Sistem Software HEROIG 


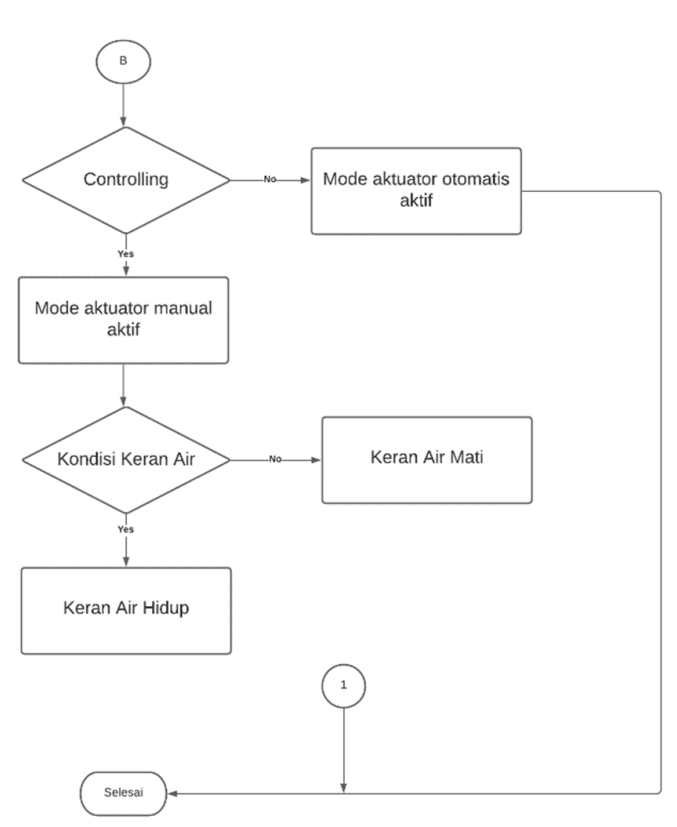

Diagram alir di atas merupakan operasi aplikasi yang terdapat menu untuk melakukan login dengan akun yang sudah teregistrasi dengan device user. Ketika user belum melakukan registrasi maka terlebih dahulu dapat membuat akun pada register activity dan kemudian user dapat masuk dalam main menu. Pa da main menu terdapat beberapa menu utama yaitu menu untuk melakukan monitoring dan controlling activity. Pada sistem HEROIG cloud server yang digunakan adalah MySQL, yang merupakan database management system yang menggunakan bahasa SQL sebagai bahasa penghubung antara perangkat lunak aplikasi dengan database server. Perancangan pada sistem database dibuat channel sebagai tempat penyimpanan data hasil sensing mikrokontroler ataupun data hasil perintah pada aplikasi.

\section{Perancangan Pengujian}

Pengujian kinerja sistem ini terfokus pada quality of service dari sistem HEROIG khususnya quality of service packet loss. Packet Loss merupakan suatu parameter yang menggambarkan suatu kondisi yang menunjukkan jumlah total paket yang hilang tidak terkirim dalam suatu jaringan dengan menggunakan rumus dari packet loss adalah [12]:

$$
\begin{aligned}
& \text { Packet Loss } \\
& =\frac{\text { Paket data terkirim }- \text { paket data diterima }}{\text { paket data terkirim }} \times 100 \%
\end{aligned}
$$

Rancangan pengujian packet loss pada pengiriman hasil sensing data sensor water flow ke cloud server terbagi menjadi 2 parameter, yaitu dari parameter jarak dan waktu untuk melihat packet loss pada sistem HEROIG.

\section{HASIL PENELITIAN DAN PEMBAHASAN}

\section{A. Pengujian Koneksi Jaringan Hotspot}

Pengujian packet loss dilakukan setelah pengujian testing koneksi jaringan hotspot dilakukan, hal ini dilakukan untuk mendapatkan parameter keberhasilan hotspot sebagai koneksi jaringan mikrokontroler untuk mengirimkan data pembacaan sensor ke cloud server seperti pada Gambar 4.8, dari jumlah paket data yang masuk dan lamanya pengambilan data

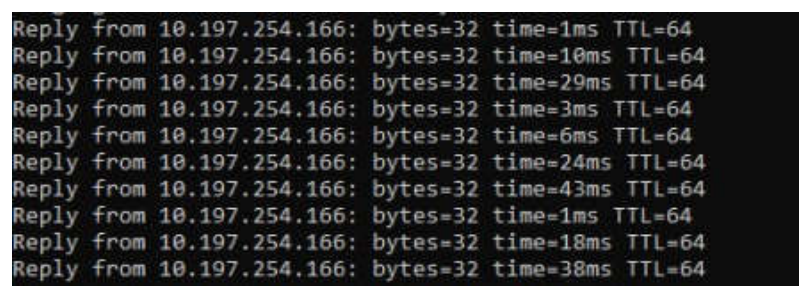

Gambar 4. 1 Testing Koneksi Jaringan Hotspot

cara melakukan testing koneksi jaringan hotspot dengan melakukan ping alamat IP yang pada device smartphone sehingga akan mendapatkan waktu perfomansi koneksi jaringan wifi pada device, dengan waktu rata-rata sekitar $1,73 \mathrm{~ms}$ atau 0,0173 detik yang diambil dari sampel 10 data di atas, berikut Tabel 4.1 menunjukkan sampel data testing yang kemudian diimplementasikan dalam bentuk grafik pada Gambar 4.2 .

Tabel 4. 1 Hasil Pengujian Permormansi Hotspot Sebagai Koneksi Jaringan

\begin{tabular}{|c|c|}
\hline Urutan Data & Waktu (ms) \\
\hline 1 & 1 \\
\hline 2 & 10 \\
\hline 3 & 29 \\
\hline
\end{tabular}


Jurnal ELECTRON, Vol. 2, No.1, Mei 2021, Hal. 10-17

e-ISSN 2622-6588

\begin{tabular}{|c|c|}
\hline 4 & 3 \\
\hline 5 & 6 \\
\hline 6 & 24 \\
\hline 7 & 43 \\
\hline 8 & 1 \\
\hline 9 & 18 \\
\hline 10 & 38 \\
\hline Waktu rata-rata & $17,3 \mathrm{~ms}$ \\
\hline
\end{tabular}

Packet Loss $=\frac{4095-4067}{4095} \times 100 \%$

Packet Loss $=0,7 \%$

Kemudian pengujian parameter waktu selanjutnya adalah dengan melihat packet loss dalam waktu 6 detik sekali dalam waktu 1 menit. Hasil pengujian packet loss dari 10 data yang diambil setiap 6 detik sekali selama 1 menit memiliki nilai rata-rata packet loss $1,13 \%$ yang memiliki indeks sangat bagus, karena memiliki packet loss dalam range 0\%-2,9\% yang ditunjukkan pada Tabel 4.2 dan diimplementasikan dalam bentuk grafik pada Gambar 4.4.

Tabel 4. 2 Hasil Pengujian Packet Loss Parameter Waktu

\begin{tabular}{|c|c|c|c|}
\hline $\begin{array}{c}\text { Waktu } \\
\text { (detik) }\end{array}$ & $\begin{array}{c}\text { Data } \\
\text { Kirim }\end{array}$ & $\begin{array}{c}\text { Data } \\
\text { Terima }\end{array}$ & $\begin{array}{c}\text { Packet } \\
\text { Loss }\end{array}$ \\
\hline 6 & 120 & 118 & $1,7 \%$ \\
\hline 12 & 131 & 128 & $2,3 \%$ \\
\hline 18 & 143 & 138 & $3,5 \%$ \\
\hline 24 & 145 & 140 & $3,4 \%$ \\
\hline 30 & 149 & 149 & $0 \%$ \\
\hline 36 & 288 & 288 & $0 \%$ \\
\hline 42 & 461 & 461 & $0 \%$ \\
\hline 48 & 859 & 858 & $0,1 \%$ \\
\hline 54 & 1504 & 1502 & $0,2 \%$ \\
\hline \multicolumn{3}{|c|}{ Rata-rata } & $1,13 \%$ \\
\hline
\end{tabular}

$713200 \mathrm{~L}$ mieves $27 \mathrm{Agt} 2021$ 1035:11 $202101270393: 11$ LOW

744300 L mirses $\quad 27$-Apr-2021 103821 2021-04-2703-3521 LOW

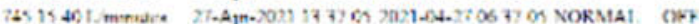

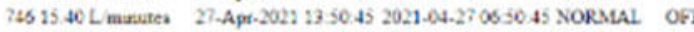

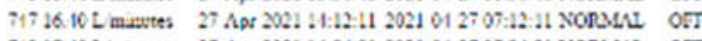

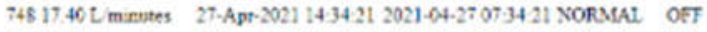

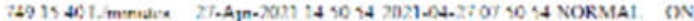

75015 to L muxutes 27.Apr.2021:451 C8 2021-04.27075t:06 NORMAL ON

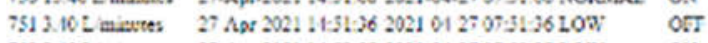

$752340 \mathrm{C}$ mirutes 27-Apr-2021 145267 2021-04-27075207 Low ov

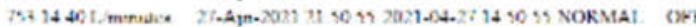

Gambar 4. 3 Pengiriman Data Sensor

Pengujian pertama yaitu dengan parameter waktu yang dilakukan pengiriman data ke cloud server selama 1 menit seperti pada Gambar 4.9 dan didapatkan hasil packet loss $0,7 \%$ dalam kategori sangat bagus karena di bawah 3\% dengan data yang terkirim 4095 data dan data yang hilang 28 sehingga packet loss dapat dicari dengan rumus sebagai berikut:

Packet Loss

$=\frac{\text { Paket data terkirim }- \text { paket data diterima }}{\text { paket data terkirim }} \times 100 \%$

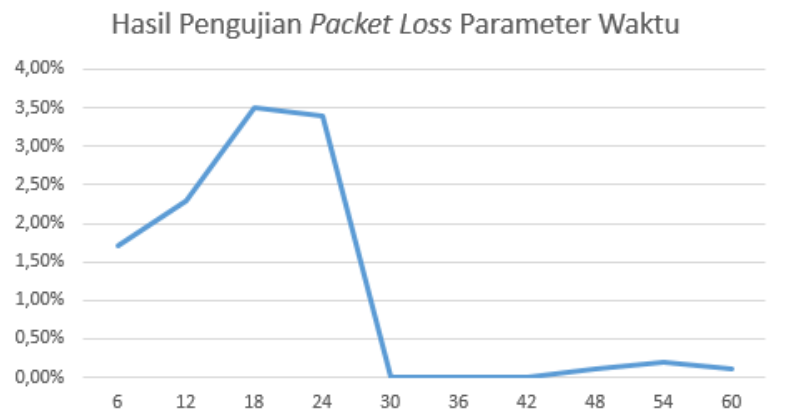

Gambar 4. 4 Hasil Pengujian Packet Loss Parameter Waktu

\section{Pengujian Packet Loss Parameter Jarak}

Pengujian packet loss parameter jarak ketika kondisi hotspot atau sumber koneksi dalam jarak 4 meter, 8 meter, 12 meter dan 16 meter dari mikrokontroller dalam waktu 1 menit, berikut hasil pengujian seperti yang ditunjukkan pada Tabel 4.3 dan diimplementasikan dalam bentuk grafik pada Gambar 4.5 . 
Tabel 4. 3 Hasil Pengujian Packet Loss Parameter Jarak

\begin{tabular}{|c|c|c|c|}
\hline $\begin{array}{c}\text { Jarak } \\
\text { (meter) }\end{array}$ & $\begin{array}{c}\text { Data } \\
\text { Kirim }\end{array}$ & $\begin{array}{c}\text { Data } \\
\text { Terima }\end{array}$ & $\begin{array}{c}\text { Packet } \\
\text { Loss }\end{array}$ \\
\hline 4 & 3667 & 3667 & $0 \%$ \\
\hline 8 & 3209 & 3206 & $0,1 \%$ \\
\hline 12 & 2946 & 2941 & $0,2 \%$ \\
\hline 16 & 666 & 664 & $0,3 \%$ \\
\hline 20 & 2351 & 2307 & $1,9 \%$ \\
\hline \multicolumn{4}{|c|}{ Rata-rata } \\
\hline
\end{tabular}

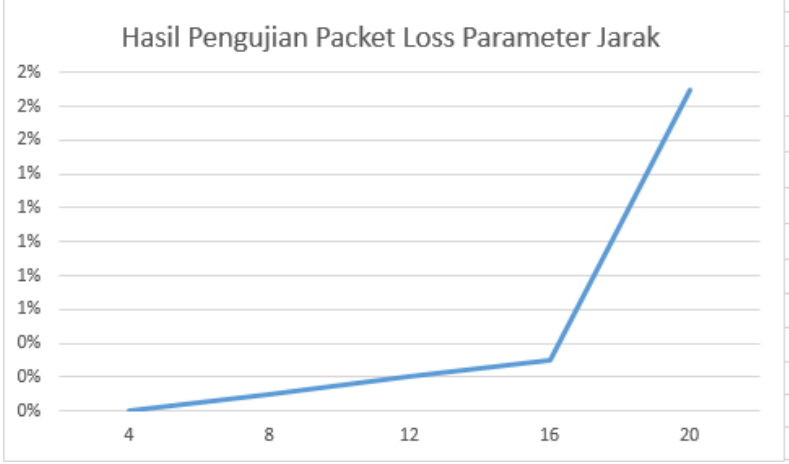

Gambar 4. 5 Grafik Pengujian Packet Loss Parameter Jarak

Dari hasil pengujian dapat diketahui nilai packet loss dengan dua parameter pengujian yaitu waktu dan jarak antara hotspot wifi dengan mikrokontroler selama satu menit. Hasil pengujian parameter waktu memiliki nilai packet loss yang sangat bagus dengan nilai rata-rata packet loss $1,3 \%$, sesuai dengan teori dasar range nilai packet loss kategori sangat bagus, kemudian hasil pengujian packet loss parameter jarak memiliki nilai rata-rata packet loss $0,5 \%$ dalam kategori indeks sangat bagus. Packet loss ini disebabkan faktor floating yang mempengaruhi konversi pada mikrokontroler dan faktor noise saat pengiriman dan penerimaan data di titik pemasangan mikrokontroler untuk mengakses koneksi jaringan internet

\section{KESIMPULAN}

Berdasarkan penelitian terkait quality of service pada sistem didapatkan kesimpulan sebagai berikut:

1. Sistem pemantauan debit air pada rumah berbasis Internet of Things (IoT) telah berhasil dikembangkan untuk melakukan monitoring dan controlling activity

2. Quality of services merupakan parameter penting untuk menentukan kualitas sistem yang berbasis Internet of Things (IoT)
3. Hasil pengujian packet loss sistem HEROIG dalam indeks sangat bagus dengan packet loss 1,13\% untuk parameter waktu dan packet loss $0,5 \%$ untuk parameter jarak.

\section{REFERENSI}

[1] S. Madonna, "EFISIENSI ENERGI MELALUI PENGHEMATAN PENGGUNAAN AIR (Studi Kasus: Institusi Pendidikan Tinggi Universitas Bakrie)," J. Tek. Sipil, vol. 12, no. 4, 2016, doi: 10.24002/jts.v12i4.635.

[2] A. Ester Suoth, "Pola Konsumsi Air Pada Perumahan Teratur: Studi Kasus Konsumsi Air Di Perumahan Griya Serpong Tangerang Selatan," J. Ecolab, vol. 12, no. 2 , pp. 62-70, 2018, doi: 10.20886/jklh.2018.12.2.62-70.

[3] H. Shull, "SISTEM PENGAMANAN PINTU RUMAH BERBASIS Internet Of Things (IoT) Dengan ESP8266," Science (80-. )., vol. 195, no. 4279, p. 639, 1977, [Online]. Available: https://ojs.uniskabjm.ac.id/index.php/JIT/article/view/661.

[4] N. Hidayati, L. Dewi, M. F. Rohmah, and S. Zahara, "Prototype Smart Home Dengan Modul NodeMCU ESP8266 Berbasis Internet of Things (IoT)," Tek. Inform. Univ. Islam Majapahit, pp. 1-9, 2018.

[5] Y. Efendi, "Internet Of Things (Iot) Sistem Pengendalian Lampu Menggunakan Raspberry Pi Berbasis Mobile," J. Ilm. Ilmu Komput., vol. 4, no. 2, pp. 21-27, 2018, doi: 10.35329/jiik.v4i2.41.

[6] S. J. Sokop, D. J. Mamahit, and S. Sompie, "Trainer Periferal Antarmuka Berbasis Mikrokontroler Arduino Uno," J. Tek. Elektro dan Komput., vol. 5, no. 3, pp. 1323, 2016.

[7] R. Chen, W. Zhai, and Y. Qi, "Mechanism and technique of friction control by applying electric voltage. (II) Effects of 
applied voltage on friction," Mосахие Xuebao/Tribology, vol. 16, no. 3, pp. 235238, 1996.

[8] A. Satriadi, Wahyudi, and Y. Christiyono, "Perancangan Home Automation Berbasis NodeMCU," Transient, vol. 8, no. 1, pp. 64-71, 2019, [Online]. Available: https://ejournal3.undip.ac.id/index.php/tran sient/article/view/22648.

[9] M. Fajar Wicaksono, "Implementasi Modul Wifi Nodemcu Esp8266 Untuk Smart Home," J. Tek. Komput. UnikomKomputika, vol. 6, no. 1, pp. 9-14, 2017.

[10] R. E. Standsyah, "Rancangan Sistem Pengadministrasian," J. UJMC, Vol. 3, Nomor 2, Hal. 38 - 44, vol. 3, pp. 38-44, 2017, [Online]. Available: http://ejurnal.unisda.ac.id/index.php/ujmc/article/ download/467/251/.

[11] B. Sugiantoro and Y. B. Mahardhika, "ANALISIS QUALITY OF SERVICE JARINGAN WIRELESS SUKANET WiFi DI FAKULTAS SAINS DAN TEKNOLOGI UIN SUNAN KALIJAGA," J. Tek. Inform., vol. 10, no. 2, pp. 191-201, 2018, doi: 10.15408/jti.v10i2.7027.

[12] F. R. Rivai, I. R. M. M. T, and U. S. S. T, "ANALISIS DAN IMPLEMENTASI PROTOTIPE PENGATUR KELEMBABAN BERBASIS INTERNET OF THINGS ( IoT ) PADA PENYIMPANAN SAYUR Analysis and Implementation Prototype of Controlling Humidity based Internet of Things ( IoT ) on Vegetable Storage," vol. 5, no. 3, pp. 4366-4373, 2018.

[13] P. T. Mahmud, "Sniffing Jaringan Menggunakan Wireshark," pp. 5-8, 2020, doi: 10.31219/osf.io/h5wu7. 